\title{
Acromegaly accompanied by diabetes mellitus and polycystic kidney disease
}

\author{
Daisuke Otani ${ }^{1), 2) *}$, Takaaki Murakami ${ }^{1), 2) *}$, Takeshi Matsubara ${ }^{3)}$, Masato Hojo ${ }^{4)}$, Takuro Nakae ${ }^{4)}$, \\ Koki Moriyoshi ${ }^{5}$, Akihiro Yasoda ${ }^{6}$, Ryota Usui ${ }^{1}$, Hisato Tatsuoka ${ }^{1}$, Masahito Ogura ${ }^{1)}$, Nobuya Inagaki ${ }^{1)}$ \\ and Taizou Yamamoto ${ }^{2)}$ \\ 1) Department of Diabetes, Endocrinology and Nutrition, Kyoto University Graduate School of Medicine, Kyoto, Japan \\ 2) Department of Diabetes and Endocrinology, Shiga General Hospital, Moriyama, Japan \\ 3) Department of Nephrology, Kyoto University Graduate School of Medicine, Kyoto, Japan \\ 4) Department of Neurosurgery, Shiga General Hospital, Moriyama, Japan \\ ${ }^{5)}$ Department of Diagnostic Pathology, National Hospital Organization Kyoto Medical Center, Kyoto, Japan \\ 6) Clinical Research Center, National Hospital Organization Kyoto Medical Center, Kyoto, Japan
}

\begin{abstract}
Acromegaly is characterized by autonomous excessive growth hormone (GH) secretion, generally due to GHproducing pituitary adenoma, and is associated with various systemic comorbidities including diabetes mellitus. Polycystic kidney disease (PKD) is characterized by the growth of numerous cysts in the kidneys that deteriorate renal function. While possible renal effects of excessive GH exposure have been a current issue in experimental medicine, only five cases of coexisting acromegaly and PKD have been reported previously, and little is known regarding the influence of acromegaly on renal disease. We treated a 50-year-old male with diabetes mellitus who showed a sudden and rapid decline of renal function along with increasing proteinuria, which led to diagnoses of PKD and acromegaly. His urinary protein levels were increased together with excessive GH secretion and worsening glycemic control. An increase of total kidney volume was also noted. Transsphenoidal surgery for the pituitary adenoma was successfully performed. Marked improvement of hyperglycemia and proteinuria were observed after the surgery, but renal function was unchanged. The patient's clinical course suggested common aspects of excessive GH secretion as an accelerating factor of the progression of diabetic nephropathy and PKD via direct and indirect pathways. Although coexisting acromegaly and PKD is clinically rare, vigilance for early diagnosis of acromegaly is appropriate in patients with diabetes and/or PKD, especially in those showing unexpected exacerbation of renal dysfunction.
\end{abstract}

Key words: Acromegaly, Diabetes mellitus, Growth hormone, Polycystic kidney disease

ACROMEGALY is an uncommon disorder characterized by autonomous and excessive secretion of growth hormone $(\mathrm{GH})$ that is generally caused by GH-producing pituitary adenoma $[1,2]$.

The annual incidence of acromegaly is reported to be approximately $3-4$ cases per million in most studies; the

Submitted Mar. 25, 2020; Accepted Jul. 22, 2020 as EJ20-0173

Released online in J-STAGE as advance publication Aug. 20, 2020

Correspondence to: Takaaki Murakami, Department of Diabetes, Endocrinology and Nutrition, Kyoto University Graduate School of Medicine, 54 Kawahara-cho, Shogoin, Sakyo-ku, Kyoto 606-8507, Japan.

E-mail: tmurakam@kuhp.kyoto-u.ac.jp

Correspondence to: Taizou Yamamoto, Department of Diabetes and Endocrinology, Shiga General Hospital, 5-4-30 Moriyama, Moriyama, Shiga 524-8524, Japan.

E-mail: taizoyamamoto@mdc.med.shiga-pref.jp

* The first two authors (D.O. and T.M.) equally contributed to this work. prevalence ranges from 85 to 133 cases per million in recent studies including in Japan [3]. Acromegaly is associated with various systemic comorbidities including cardiovascular disease, metabolic complications (hyperglycemia and hyperlipidemia), respiratory diseases, osteoarthropathy, vertebral fractures, and possible increased risks of some neoplasms and with increased mortality when not adequately treated $[2,3]$. The prevalence of diabetes mellitus in patients with acromegaly has been reported to be higher than that in the normal population, ranging from 11 to $53 \%$ [3]. Although GH stimulates insulin secretion, the hormone predominantly induces insulin resistance by countering the actions of insulin and subsequently increasing the prevalence of diabetes mellitus [3].

Polycystic kidney disease (PKD) is a renal disorder characterized by growth of numerous cysts in the kidneys that replace renal parenchyma and deteriorate renal 
function [4]. There are two types of PKD: autosomal dominant PKD (ADPKD) caused by germline mutation in the PKD1 and PKD2 genes, which is usually diagnosed in adulthood, and autosomal recessive PKD (ARPKD), which is typically identified in the first few weeks after birth. ADPKD is estimated to affect one individual per 4,033 of the population in Japan [5], and is responsible for 5 to $10 \%$ of cases of end-stage kidney disease [4]. Affected patients typically present with enlarged kidneys with bilateral multiple cysts [6]. Kidney volume, as well as proteinuria and glomerular filtration rate (GFR), can be used as markers for disease progression; changes in renal function are strongly associated with kidney volume in Japanese ADPKD patients [7].

Although a few cases of coexisting acromegaly and ADPKD have been reported [8-12], little is known of the influence of acromegaly on the severity and progression of PKD, especially in cases that also have diabetic nephropathy. We report here a rare case of acromegaly accompanied by both diabetes mellitus and PKD that presented with a rapid decrease of renal function and an increase of total kidney volume. The present case highlights potential effects of excessive GH secretion on kidney function and structure as well as the clinical importance of vigilance for acromegaly in cases with diabetes and its related progressive renal dysfunction and PKD.

\section{Case Presentation}

A 50-year-old male with progressively worsening glycemic control was referred to our clinic for treatment of diabetes mellitus. He had no family history of diabetes, pituitary or other endocrine tumors including multiple endocrine neoplasia type 1. Although he had no firm family history of PKD, his father had hypertension and died of ruptured aortic aneurism, but no more detailed clinical information on renal diseases was available. Our patient did not have any dietary restrictions and denied consuming alcohol.

His medical history revealed that he was on medication including valsartan (160 mg per day), amlodipine (10 mg per day) and carvedilol (20 mg per day) for hypertension since he was 36 years old. At 46 years of age, he was diagnosed with type 2 diabetes mellitus based on a hemoglobin A1c (HbA1c) level of $9.7 \%$ and a blood glucose level of $399 \mathrm{mg} / \mathrm{dL}$ with a negative result for anti-glutamic acid decarboxylase antibody, and was prescribed metformin (500 mg per day) and glimepiride (0.5 mg per day). At the time of his initial diagnosis of diabetes, no findings suggesting diabetic nephropathy [urinalysis protein: negative, urine albumin/creatinine
(Cr) ratio: $7.1 \mathrm{mg} / \mathrm{gCr}$ ] or retinopathy were observed. Nine months later, he presented with microalbuminuria [urine albumin/Cr ratio: $285.5 \mathrm{mg} / \mathrm{gCr}$ ]. At 48 years of age, overt proteinuria developed [urine protein $/ \mathrm{Cr}$ ratio (UPCR): $0.96 \mathrm{~g} / \mathrm{gCr}$, serum $\mathrm{Cr}(\mathrm{SCr}): 0.96 \mathrm{mg} / \mathrm{dL}$, estimated GFR (eGFR): $67 \mathrm{~mL} / \mathrm{min} / 1.73 \mathrm{~m}^{2}$ ], although his HbA1c level was maintained up to $6.4 \%$ under the above-mentioned medical treatment. However, at 50 years of age, the patient's glycemic control worsened (HbA1c: 7.6\%), and he developed bilateral preproliferative diabetic retinopathy. He was then referred to our clinic (Fig. 1).

At his first visit, his UPCR was increased to 1.20 $\mathrm{g} / \mathrm{gCr}$ concomitantly with a decline in eGFR (40 $\mathrm{mL} / \mathrm{min} / 1.73 \mathrm{~m}^{2}$ ). Abdominal ultrasonography and magnetic resonance imaging (MRI) revealed enlarged kidneys with bilateral multiple cysts (Fig. 2A, 2B), which suggested PKD. The estimated total kidney volume (TKV) was 1,078 $\mathrm{mL}$. Renal biopsy was not undertaken because of the numerous renal cysts. After transient improvement of his glycemic control possibly due to additional nutritional guidance, his $\mathrm{HbAlc}$ became elevated again, and his UPCR rapidly increased (Fig. 1). During the follow-up, a careful re-interview revealed that the patient had noticed gradual enlargement of his hands and feet over several years. In addition to the treatmentrefractory non-insulin-dependent diabetes, his coarsened facial features and enlargement of hands and feet led to suspicion of acromegaly. He was therefore admitted for further evaluation.

On admission, he was alert; height, $187 \mathrm{~cm}$; weight, $88 \mathrm{~kg}$; pulse, 63 beats per minute; and blood pressure, $117 / 83 \mathrm{mmHg}$. He was prescribed metformin [500 mg semel in die (s.i.d.)], glimepiride $(0.5 \mathrm{mg}$ s.i.d.), valsartan (160 mg s.i.d.), amlodipine (10 mg s.i.d.) and carvedilol (20 mg s.i.d.).

Laboratory data on admission is shown in Table 1 . The diagnosis of acromegaly was confirmed by his clinical features as follows: (i) the serum insulin-like growth factor 1 (IGF-1) level was $718 \mathrm{ng} / \mathrm{mL}$ (normal reference range: 87 to $245 \mathrm{ng} / \mathrm{mL}$ ); (ii) the serum $\mathrm{GH}$ level was elevated at baseline $(8.16 \mathrm{ng} / \mathrm{mL})$ and was not appropriately suppressed (nadir: $6.72 \mathrm{ng} / \mathrm{mL}$ ) during $75 \mathrm{~g}$ oral glucose tolerance test; (iii) and pituitary MRI revealed a sellar mass of $9 \mathrm{~mm}$ in diameter [13]. The mass showed a low signal intensity on the T2-weighted images and had a hyperintense lesion suggesting Rathke's cleft cysts (Fig. 3). Ankle radiography demonstrated heel pad thickness $(23 \mathrm{~mm})$, which was consistent with the diagnosis of acromegaly.

Endocrine data also showed hyperprolactinemia, subclinical hyperthyroidism and an elevated serum thyroglobulin (Tg) level (Table 1). Anti-TSH receptor, 


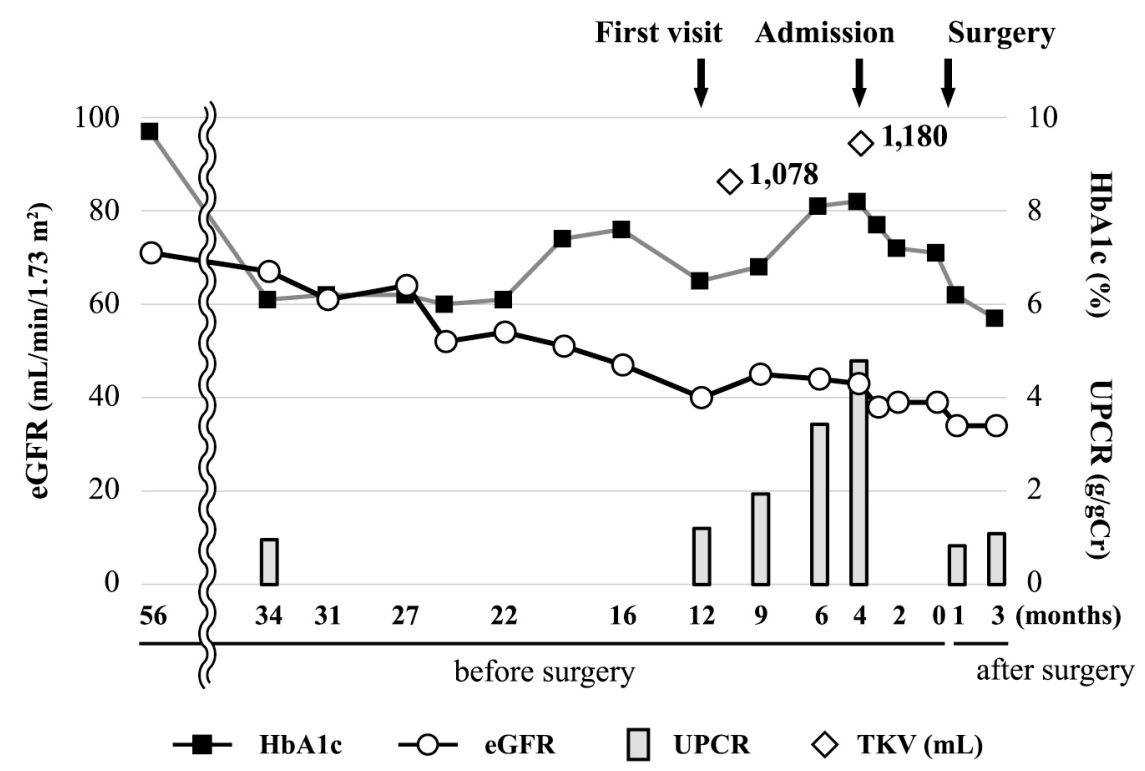

Fig. 1 Clinical course of the present case.

A sudden and rapid decline of renal function along with increasing proteinuria, which led to diagnoses of PKD and acromegaly, were shown. Marked improvement of hyperglycemia and proteinuria were observed after the transsphenoidal surgery, but renal function was unchanged.

Changes in hemoglobin A1c (HbAlc) levels, estimated glomerular filtration rate (eGFR), urine protein/creatinine ratio (UPCR) and estimated total kidney volume (TKV). Black boxes; HbA1c levels, white circles; eGFR, gray bars; UPCR, TKV; white rhombi.
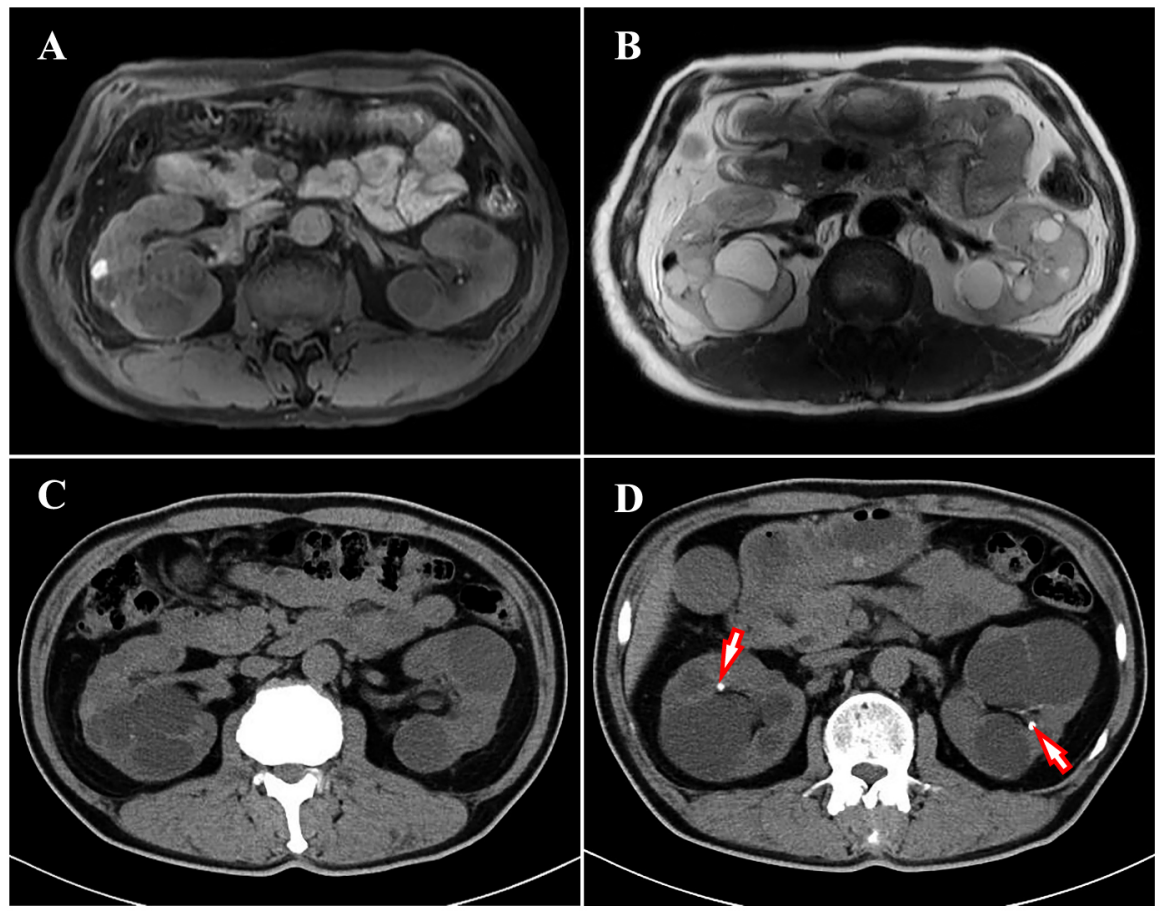

Fig. 2 Abdominal images demonstrating enlarged kidneys with multiple cysts.

Representative images of axial magnetic resonance imaging (MRI) at the referral (A; T1-weighted, B; T2-weighted) and axial computed tomography (CT) scan on admission (C, D) are shown. Bilateral renal stones are indicated by red arrows. 
Table 1 Laboratory data on admission

\begin{tabular}{|c|c|c|c|}
\hline White blood cell & $4,400 / \mu \mathrm{L}$ & $\mathrm{GH}$ & $8.16 \mathrm{ng} / \mathrm{mL}$ \\
\hline Red blood cell & $411 \times 10^{4} / \mu \mathrm{L}$ & IGF-1 & $718 \mathrm{ng} / \mathrm{mL}$ \\
\hline Hemoglobin & $12.5 \mathrm{~g} / \mathrm{dL}$ & $\mathrm{TSH}$ & $0.02 \mu \mathrm{IU} / \mathrm{mL}$ \\
\hline Hematocrit & $36.8 \%$ & Free T4 & $1.32 \mathrm{ng} / \mathrm{dL}$ \\
\hline Platelet & $23.2 \times 10^{4} / \mu \mathrm{L}$ & Free T3 & $3.67 \mathrm{pg} / \mathrm{mL}$ \\
\hline Total protein & $7.4 \mathrm{~g} / \mathrm{dL}$ & PRL & $19.00 \mathrm{ng} / \mathrm{mL}$ \\
\hline Albumin & $3.9 \mathrm{~g} / \mathrm{dL}$ & $\mathrm{ACTH}$ & $32.9 \mathrm{pg} / \mathrm{mL}$ \\
\hline Total bilirubin & $0.96 \mathrm{mg} / \mathrm{dL}$ & Cortisol & $6.92 \mu \mathrm{g} / \mathrm{dL}$ \\
\hline AST & $13 \mathrm{U} / \mathrm{L}$ & LH & $2.89 \mathrm{mIU} / \mathrm{mL}$ \\
\hline ALT & $9 \mathrm{U} / \mathrm{L}$ & FSH & $2.23 \mathrm{mIU} / \mathrm{mL}$ \\
\hline LDH & $163 \mathrm{U} / \mathrm{L}$ & Free testosterone & $9.1 \mathrm{pg} / \mathrm{mL}$ \\
\hline ALP & $192 \mathrm{U} / \mathrm{L}$ & & \\
\hline$\gamma$-GTP & $21 \mathrm{U} / \mathrm{L}$ & $\mathrm{TRAb}$ & $(-)$ \\
\hline Cholinesterase & $361 \mathrm{U} / \mathrm{L}$ & TSAb & $103 \%$ \\
\hline Creatinine & $1.35 \mathrm{mg} / \mathrm{dL}$ & Anti-TPO antibody & $(-)$ \\
\hline BUN & $14.6 \mathrm{mg} / \mathrm{dL}$ & Anti-Tg antibody & $(-)$ \\
\hline Uric acid & $4.4 \mathrm{mg} / \mathrm{dL}$ & $\mathrm{Tg}$ & $162.00 \mathrm{ng} / \mathrm{mL}$ \\
\hline Total cholesterol & $197 \mathrm{mg} / \mathrm{dL}$ & & \\
\hline HDL cholesterol & $38 \mathrm{mg} / \mathrm{dL}$ & Urinalysis & \\
\hline Triglyceride & $356 \mathrm{mg} / \mathrm{dL}$ & Protein & $4.79 \mathrm{~g} / \mathrm{gCr}$ \\
\hline $\mathrm{Na}$ & $141 \mathrm{mEq} / \mathrm{L}$ & Occult blood & $(+)$ \\
\hline K & $3.2 \mathrm{mEq} / \mathrm{L}$ & Glucose & $(+)$ \\
\hline $\mathrm{Cl}$ & $98 \mathrm{mEq} / \mathrm{L}$ & Urinary NAG & $12.2 \mathrm{U} / \mathrm{L}$ \\
\hline $\mathrm{Ca}$ & $9.8 \mathrm{mg} / \mathrm{dL}$ & Urinary $\beta 2-\mathrm{MG}$ & $4,270 \mu \mathrm{g} / \mathrm{L}$ \\
\hline BNP & $6.0 \mathrm{pg} / \mathrm{mL}$ & & \\
\hline \multirow[t]{2}{*}{ Glycated albumin } & $22.6 \%$ & 24-hour urine collection test & \\
\hline & & Urinary creatinine & $1,958.4 \mathrm{mg} /$ day \\
\hline FPG & $257 \mathrm{mg} / \mathrm{dL}$ & Urinary protein & 4,885 mg/day \\
\hline \multirow[t]{2}{*}{$\mathrm{HbAlc}$} & $8.2 \%$ & Urinary CPR & $203.0 \mu \mathrm{g} /$ day \\
\hline & & Fecal occult blood & $(-)$ \\
\hline
\end{tabular}

AST, aspartate aminotransferase; ALT, alanine aminotransferase; LDH, lactate dehydrogenase; ALP, alkaline phosphatase; $\gamma$-GTP, $\gamma$-glutamyl transpeptidase; BUN, blood urea nitrogen; HDL, high density lipoprotein; FPG, fasting plasma glucose; HbA1c, hemoglobin A1c; BNP, brain natriuretic peptide; $\mathrm{GH}$, growth hormone; IGF-1, insulin-like growth factor 1; TSH, thyroid stimulating hormone; T4, thyroxine; T3, triiodothyronine; PRL, prolactin; ACTH, adrenocorticotropic hormone; LH, luteinizing hormone; FSH, follicle stimulating hormone; TRAb, TSH receptor antibody; TSAb, thyroid stimulating antibody; TPO, thyroid peroxidase; Tg, thyroglobulin; NAG, N-acetyl- $\beta-\mathrm{D}-$ glucosaminidase; $\beta 2-\mathrm{MG}, \beta 2$-microglobulin; $\mathrm{CPR}$, C-peptide immunoreactivity.

anti-thyroid peroxidase (TPO) and anti-Tg antibodies were negative. Thyroid ultrasonography revealed enlarged thyroid gland, while technetium-99m pertechnetate thyroid scintigraphy showed diffusely suppressed uptake in thyroid gland $(0.3 \%)$, suggesting destructive thyroiditis. The TSH and prolactin (PRL) responses to intravenous thyrotropin-releasing hormone (TRH) were blunted, whereas corticotropin-releasing hormone (CRH)-stimulated ACTH and cortisol responses and luteinizing hormone releasing hormone (LHRH)stimulated gonadotropin responses were normal.

Renal data revealed that UPCR and eGFR were 4.79 


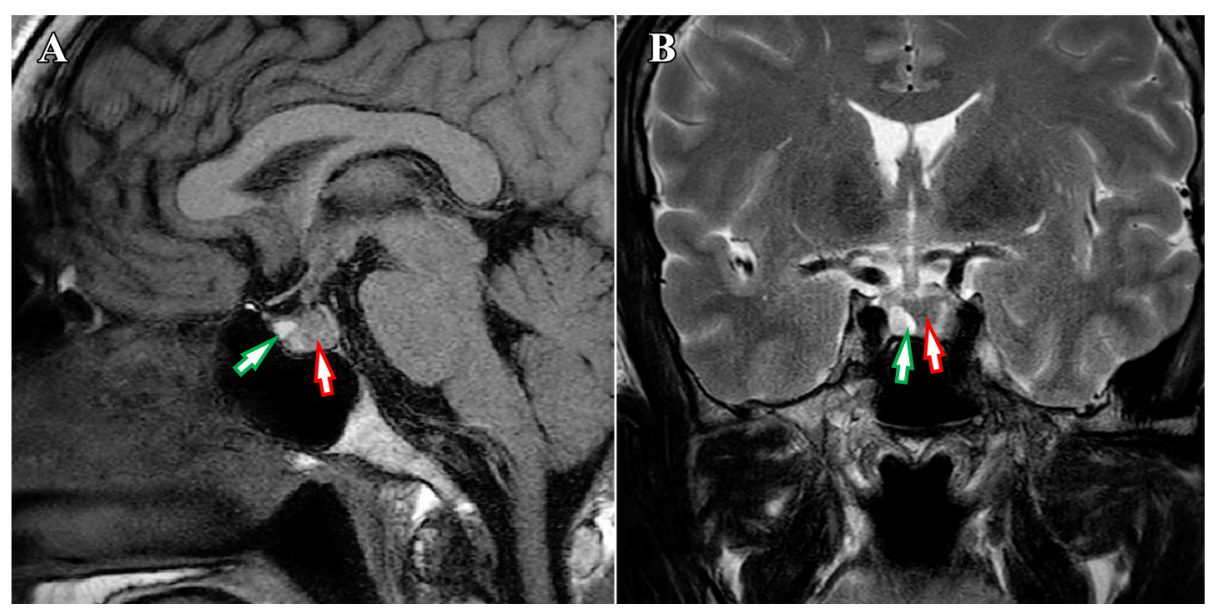

Fig. 3 MR images of the pituitary tumor.

Non-contrast sagittal T1-weighted (A) and coronal T2-weighted (B) pituitary magnetic resonance images are shown. A sellar mass is indicated by red arrows. The mass shows signal hypointensity on the T2-weighted images, which is compatible with denselygranulated somatotroph adenoma. Cystic lesions (indicated by green arrows) show signal hyperintensity on the T1-weighted and T2-weighted images, which is compatible with Rathke's cleft cysts.

$\mathrm{g} / \mathrm{gCr}$ and $43 \mathrm{~mL} / \mathrm{min} / 1.73 \mathrm{~m}^{2}$, respectively. Abdominal computed tomography (CT) scan showed growth of renal cysts as well as bilateral kidney stones (Fig. 2C, 2D). The estimated TKV was 1,180 mL. Magnetic resonance angiography (MRA) of the brain showed fusiform aneurysmal dilatations of the proximal A2 segment of the left anterior cerebral and basilar arteries. Echocardiography revealed left ventricular hypertrophy without evident valve abnormalities.

Three months after admission, transsphenoidal surgery for pituitary tumor was performed. The tumor was intraoperatively found to be white-colored. In addition, the cystic lesions within the pituitary tumor contained colorless and white mucous fluids with a thin ciliated epithelium layer, which suggested Rathke's cleft cysts when considered with the MRI findings [14]. Pathological examination of the tumor revealed sheet-like cells with oval nuclei and acidophilic or amphophilic cytoplasm, which is consistent with pituitary adenoma (Fig. 4A, 4B). Immunostaining for GH and PRL were positive (Fig. 4C, 4D) and anti-Cytokeratin (CAM 5.2) immunohistochemistry showed mainly a perinuclear pattern of keratin filaments, indicating the structural features similar to densely-granulated somatotroph adenoma (Fig. $4 \mathrm{E}$ ), in accord with the hypointense signal pattern on the T2-weighted MRI images (Fig. 3B) [15, 16]. The Ki-67 labeling index was less than 5\% (Fig. 4F). Postoperative serum GH and IGF-1 levels were normalized (0.92 $\mathrm{ng} / \mathrm{mL}$ and $170 \mathrm{ng} / \mathrm{mL}$, respectively), indicating successful surgical resection of the GH-producing pituitary adenoma. Three months after surgery, HbAlc level and UPCR were markedly decreased $(5.7 \%$ and $1.09 \mathrm{~g} / \mathrm{gCr}$, respectively), but eGFR was unchanged $(34 \mathrm{~mL} / \mathrm{min} /$ $1.73 \mathrm{~m}^{2}$ ) (Fig. 1).

\section{Discussion}

We report a very rare case of acromegaly concomitant with diabetes mellitus and PKD. In the present case, the patient showed relatively early development of albuminuria and rapid progression of overt proteinuria and renal impairment, which was partly improved by surgical resection of the GH-producing pituitary adenoma. To our knowledge, the first case report of acromegaly associated with ADPKD was reported in 2002 [8]; four other cases have since been reported [9-12] and all of the affected individuals were female (Table 2). The present case shows that this combination of diseases can also occur in males. Ruggenenti et al. briefly mentioned an ADPKD patient with a pituitary adenoma who had been on continued treatment with the somatostatin analogue octreotide for 2 years to control GH secretion [9]. Detailed data regarding renal function and kidney volume is unavailable in all five cases. In this report, we describe in detail long-term renal changes in a case with acromegaly accompanied by diabetes mellitus and PKD that highlights the necessity of clinical vigilance for acromegaly and PKD in unusual cases of diabetes mellitus. In addition, this case provides clues to the pathological relationship between excessive GH and kidney disease, not only via direct pathways but also indirect pathways such as diabetic nephropathy.

Delayed diagnosis of acromegaly remains a clinical issue [3]. In the present case, underlying acromegaly 

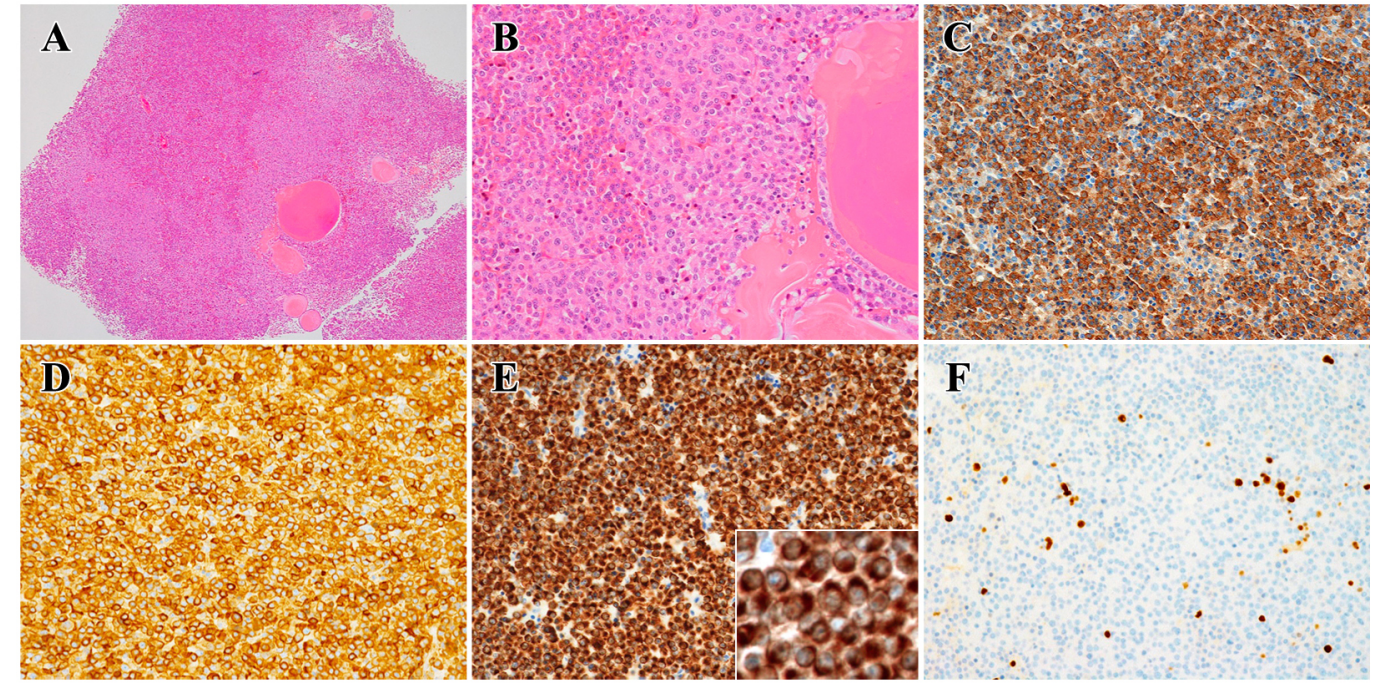

Fig. 4 Pathological images of the pituitary tumor.

The pituitary tumor samples stained with hematoxylin and eosin (H\&E) (A; low-power field, B; high-power field), anti-GH antibody (C), anti-PRL antibody (D), anti-cytokeratin antibody (CAM 5.2) (E) and anti-Ki67 antibody (F) are shown. Original magnification, A; ×40, B-F: $\times 200$, inset of E; $\times 400$.

Table 2 Summary of previous case reports on acromegaly accompanied by ADPKD

\begin{tabular}{|c|c|c|c|c|c|c|c|}
\hline Authors & Age/Sex & $\begin{array}{c}\mathrm{GH} \\
(\mathrm{ng} / \mathrm{mL})\end{array}$ & $\begin{array}{c}\text { IGF-1 } \\
(\mathrm{ng} / \mathrm{mL})\end{array}$ & Treatment & $\begin{array}{l}\text { Outcome of } \\
\text { acromegaly }\end{array}$ & $\begin{array}{l}\text { Renal } \\
\text { function }\end{array}$ & $\begin{array}{l}\text { Cystic } \\
\text { lesions }\end{array}$ \\
\hline Fajfr R, et al. (2002) [8] & $24 / \mathrm{F}$ & $5.7^{*}$ & $\begin{array}{c}569 \\
(230-546)^{\#}\end{array}$ & TSS & Recovered & NA & NA \\
\hline $\begin{array}{l}\text { Ruggenenti P, et al. (2005) } \\
\text { [9] }\end{array}$ & $\mathrm{NA} / \mathrm{F}$ & NA & NA & Octreotide & NA & NA (stable) & Stable \\
\hline $\begin{array}{l}\text { Kannabiran M, et al. } \\
(2006)[10]\end{array}$ & $50 / \mathrm{F}$ & NA & NA & TSS & Recovered & NA & NA \\
\hline Syro LV, et al. (2012) [11] & $39 / \mathrm{F}$ & $90^{*}$ & $\begin{array}{c}811 \\
(48-255)^{\#}\end{array}$ & $\begin{array}{l}\text { TSS (subtotal), } \\
\text { Octreotide }\end{array}$ & Controlled & Normal & Stable \\
\hline $\begin{array}{l}\text { Mangaraj S, et al. (2019) } \\
\text { [12] }\end{array}$ & $42 / \mathrm{F}$ & $34.3 *$ & $\begin{array}{c}644 \\
(101-267)^{\#}\end{array}$ & $\begin{array}{c}\text { TSS (subtotal), } \\
\text { Octreotide, } \\
\text { Radiotherapy }\end{array}$ & Uncontrolled & NA & NA \\
\hline
\end{tabular}

GH, growth hormone; IGF-1, insulin-like growth factor 1; F, female; NA, not available; TSS, transsphenoidal surgery; *, GH values during the oral glucose tolerance test; ${ }^{\#}$, reference ranges of IGF-1.

may have affected his glycemic control, as improvement was observed after surgery. Furthermore, treatmentrefractory non-insulin-dependent diabetes mellitus can lead to untested suspicion of acromegaly in clinical settings [3].

Undiagnosed acromegaly can affect renal impairment indirectly via worsened glycemic control status; the increase of $\mathrm{HbA} 1 \mathrm{c}$ in the present case appeared to affect the patient's UPCR levels. There is accumulating evidence that the GH/IGF-1 axis plays an important role in early development of diabetic kidney disease $[17,18]$. In fact, IGF-1 induces mesangial cell proliferation as well as mesangial matrix production [19], and appears to protect mesangial cells from DNA damage induced by hyperglycemia [20]. Hence, GH is implicated in glomerular hypertrophy via IGF-1, even though some effects of GH on glomerular sclerosis are independent of IGF-1 [21]. In addition, it was recently demonstrated that $\mathrm{GH}$ directly increases the levels of reactive oxygen species and induces actin cytoskeleton reorganization in glomerular podocytes via functional GH receptors expressed on these cells [22]. This might cause apoptosis and dysfunction of glomerular podocytes [23, 24], an early event in diabetic nephropathy.

Interestingly, relatively early development of albuminuria was found after the patient's diagnosis of diabetes mellitus in the present case. Moreover, he developed persistent proteinuria even under acceptable glycemic 
control status. After clinical follow-up under the assumption of diabetic nephropathy, PKD was found to be another cause of his proteinuria and renal impairment, based on abdominal ultrasonography and MRI findings. Although our case lacks firm family history of PKD, his father died of ruptured aortic aneurism; a previous study found that family history was absent in 20 to $40 \%$ of ADPKD patients in whom the diagnosis of ADPKD was established based on imaging studies [6]. In this context, kidney imaging tests such as ultrasonography, MRI and $\mathrm{CT}$ are warranted in diabetic cases presenting with early development of albuminuria and unexpected progression to proteinuria and renal dysfunction to ensure prompt diagnosis of PKD.

It has been established that prolonged exposure to $\mathrm{GH}$ and IGF-1 hypersecretion can be associated with morphological changes in the kidneys and the pathogenesis of PKD [25]. In mice transgenic for human GH, severe renal alterations including massive cystic dilation of the tubule has been observed [26]. In the kidneys of the mouse model of PKD, the mRNA expression of IGF-1 was increased with the progression of cystic lesions [27]. Similarly, kidney IGF-1 levels correlated positively with progression of disease in the rat model of PKD, whereas diet-induced lowering of kidney IGF-1 levels resulted in reduction of renal and cyst size [28]. In addition, polycystin-1 deficiency in PKD1 cystic cell lines has been associated with increased sensitivity to IGF-1 as well as to a permissive effect of cyclic adenosine monophosphate (cAMP) on cell growth [29]. Another study demonstrated that the GH-signal transducer and activator of the transcription (STAT) axis was abnormally activated in PKD1-deficient mice, leading to enhanced proliferation [30]. Considering the fact that activated STAT3 was found to be strongly expressed in tubular epithelial cells from kidneys of patients with simple renal cysts [31], possible implication of STAT3 activation by GH in renal cyst development was suggested [32]. This evidence suggests that GH and IGF-1 might play a pathogenic role in PKD.
In this context, TKV in the present case, which was measured by stereology using abdominal MRI or CT, should be discussed. Based on the longitudinal mixedeffect regression model described by Irazabal et al. [33], our patient was classified as Class 1B [his heightadjusted TKV (HtTKV) at 50 years of age: $576.5 \mathrm{~mL} / \mathrm{m}$ ], in which the estimated growth rate of HtTKV is 1.5 to $3 \%$ per year. In contrast, his HtTKV on admission was $631.0 \mathrm{~mL} / \mathrm{m}$, and the growth rate reached $9 \%$ within one year. Although post-operative follow-up of TKV would be helpful to confirm the involvement of acromegaly in the progression of PKD, the post-operative kidney imaging tests could not be been obtained due to the patient's discontinuation of regular visits. Given the potentially rapid increase of HtTKV, further investigation regarding the association of acromegaly with the progression of PKD is desirable, even though their occurrence together is clinically very rare.

Finally, possible use of tolvaptan in the present case should be mentioned. Tolvaptan is a vasopressin V2 receptor antagonist, which was approved for ADPKD in 2014 in Japan. Since previous studies showed tolvaptan reduced the annual rate of TKV growth and slowed the annual rate of eGFR decline in later-stage ADPKD patients $[34,35]$, it can be considered as a future treatment option in such cases.

In conclusion, we report a case of acromegaly accompanied by diabetes mellitus and PKD. Rapidly worsening proteinuria and renal function suggests common aspects of excessive $\mathrm{GH}$ secretion as an accelerating factor of both diabetic nephropathy and PKD. Although coexisting acromegaly and PKD is clinically rare, vigilance for early diagnosis of acromegaly as well as PKD is appropriate in patients with unusual diabetes or unexpected exacerbation of proteinuria and renal dysfunction.

\section{Disclosure}

None of the authors have any potential conflicts of interest associated with this report.

\section{References}

1. Melmed S (2006) Medical progress: acromegaly. $N$ Engl J Med 355: 2558-2573.

2. Melmed S (2009) Acromegaly pathogenesis and treatment. J Clin Invest 119: 3189-3202.

3. Gadelha MR, Kasuki L, Lim DST, Fleseriu M (2019) Systemic complications of acromegaly and the impact of the current treatment landscape: an update. Endocr Rev 40: 268-332.

4. Wilson PD (2004) Polycystic kidney diseases. $N$ Engl $J$ Med 350: 151-162.
5. Horie S, Mochizuki T, Muto S, Hanaoka K, Fukushima Y, et al. (2016) Evidence-based clinical practice guidelines for polycystic kidney disease 2014. Clin Exp Nephrol 20: 493-509.

6. Pei Y (2006) Diagnostic approach in autosomal dominant polycystic kidney disease. Clin J Am Soc Nephrol 1: $1108-1114$.

7. Tokiwa S, Muto S, China T, Horie S (2011) The relationship between renal volume and renal function in autosomal dominant polycystic kidney disease. Clin Exp Nephrol 
15: 539-545.

8. Fajfr R, Müller B, Diem P (2002) Hypophyseal incidentaloma in a patient with autosomal dominant polycystic kidney disease. Praxis (Bern 1994) 91: 1123-1126 (In German).

9. Ruggenenti P, Remuzzi A, Ondei P, Fasolini G, Antiga L, et al. (2005) Safety and efficacy of long-acting somatostatin treatment in autosomal-dominant polycystic kidney disease. Kidney Int 68: 206-216.

10. Kannabiran M, Singh V, Grewal S (2006) Acromegaly presenting as psychotic disorder in a family with familial autosomal dominant polycystic kidney disease. Ger J Psychiatry 9: 136-138.

11. Syro LV, Sundsbak JL, Scheithauer BW, Toledo RA, Camargo M, et al. (2012) Somatotroph pituitary adenoma with acromegaly and autosomal dominant polycystic kidney disease: SSTR5 polymorphism and PKD1 mutation. Pituitary 15: 342-349.

12. Mangaraj S, Patro D, Choudhury AK, Baliarsinha AK (2019) A rare case of acromegaly and autosomal dominant polycystic kidney disease: case report and brief review of literature. AACE Clin Case Rep 5: e302-e306.

13. The hypothalamic-pituitary dysfunction study group of the Ministry of Health Labour and Welfare (2019) Diagnosis and treatment of hypothalamic pituitary dysfunction. Nihon Naibunpi Gakkai Zasshi 95 Suppl: 1-60 (In Japanese).

14. Nishio S, Fujiwara S, Morioka T, Fukui M (1995) Rathke's cleft cysts within a growth hormone producing pituitary adenoma. Br J Neurosurg 9: 51-55.

15. Heck A, Emblem KE, Casar-Borota O, Bollerslev J, Ringstad G (2016) Quantitative analyses of T2-weighted MRI as a potential marker for response to somatostatin analogs in newly diagnosed acromegaly. Endocrine 52: 333-343.

16. Akirov A, Asa SL, Amer L, Shimon I, Ezzat S (2019) The clinicopathological spectrum of acromegaly. J Clin Med 8: 1962.

17. Flyvbjerg A (2000) Putative pathophysiological role of growth factors and cytokines in experimental diabetic kidney disease. Diabetologia 43: 1205-1223.

18. Vasylyeva TL, Ferry RJ Jr (2007) Novel roles of the IGFIGFBP axis in etiopathophysiology of diabetic nephropathy. Diabetes Res Clin Pract 76: 177-186.

19. Feld SM, Hirschberg R, Artishevsky A, Nast C, Adler SG (1995) Insulin-like growth factor I induces mesangial proliferation and increases mRNA and secretion of collagen. Kidney Int 48: 45-51.

20. Yang S, Chintapalli J, Sodagum L, Baskin S, Malhotra A, et al. (2005) Activated IGF-1R inhibits hyperglycemiainduced DNA damage and promotes DNA repair by homologous recombination. Am J Physiol Renal Physiol 289: F1144-F1152.

21. Baud L, Fouqueray B, Bellocq A, Doublier S, Dumoulin A (1999) Growth hormone and somatostatin in glomerular injury. J Nephrol 12: 18-23.

22. Reddy GR, Pushpanathan MJ, Ransom RF, Holzman LB,
Brosius FC, et al. (2007) Identification of the glomerular podocyte as a target for growth hormone action. Endocrinology 148: 2045-2055.

23. Pagtalunan ME, Miller PL, Jumping-Eagle S, Nelson RG, Myers BD, et al. (1997) Podocyte loss and progressive glomerular injury in type II diabetes. $J$ Clin Invest 99: 342-348.

24. Kumar PA, Kotlyarevska K, Dejkhmaron P, Reddy GR, Lu C, et al. (2010) Growth hormone (GH)-dependent expression of a natural antisense transcript induces zinc finger E-box-binding homeobox 2 (ZEB2) in the glomerular podocyte: a novel action of $\mathrm{GH}$ with implications for the pathogenesis of diabetic nephropathy. $\mathrm{J}$ Biol Chem 285: 31148-31156.

25. Kamenický P, Mazziotti G, Lombès M, Giustina A, Chanson P, et al. (2014) Growth hormone, insulin-like growth factor-1, and the kidney: pathophysiological and clinical implications. Endocr Rev 35: 234-281.

26. Wanke R, Hermanns W, Folger S, Wolf E, Brem G (1991) Accelerated growth and visceral lesions in transgenic mice expressing foreign genes of the growth hormone family: an overview. Pediatr Nephrol 5: 513-521.

27. Nakamura T, Ebihara I, Nagaoka I, Tomino Y, Nagao S, et al. (1993) Growth factor gene expression in kidney of murine polycystic kidney disease. J Am Soc Nephrol 3: 1378-1386.

28. Aukema HM, Housini I (2001) Dietary soy protein effects on disease and IGF-I in male and female Han: SPRD-cy rats. Kidney Int 59: 52-61.

29. Parker E, Newby LJ, Sharpe CC, Rossetti S, Streets AJ, et al. (2007) Hyperproliferation of PKD1 cystic cells is induced by insulin-like growth factor-1 activation of the Ras/Raf signalling system. Kidney Int 72: 157-165.

30. Fragiadaki M, Lannoy M, Themanns M, Maurer B, Leonhard WN, et al. (2017) STAT5 drives abnormal proliferation in autosomal dominant polycystic kidney disease. Kidney Int 91: 575-586.

31. Liu M, Xu YF, Feng Y, Zhai W, Che JP, et al. (2013) Androgen-STAT3 activation may contribute to gender disparity in human simply renal cysts. Int J Clin Exp Pathol 6: 686-694.

32. Yamamoto $M$, Matsumoto $R$, Fukuoka H, Iguchi $G$, Takahashi M, et al. (2016) Prevalence of simple renal cysts in acromegaly. Intern Med 55: 1685-1690.

33. Irazabal MV, Rangel LJ, Bergstralh EJ, Osborn SL, Harmon AJ, et al. (2015) Imaging classification of autosomal dominant polycystic kidney disease: a simple model for selecting patients for clinical trials. J Am Soc Nephrol 26: $160-172$.

34. Torres VE, Chapman AB, Devuyst O, Gansevoort RT, Perrone RD, et al. (2017) Tolvaptan in later-stage autosomal dominant polycystic kidney disease. $N$ Engl $J$ Med 377: 1930-1942.

35. Oguro M, Kogure Y, Hoshino J, Ubara Y, Mizuno H, et al. (2018) Tolvaptan in Japanese patients with later-stage autosomal dominant polycystic kidney disease. J Nephrol 31: 961-966. 